\title{
Social Media in Health Education, Promotion, and Communication: Reaching Rural Hispanic Populations along the USA/Mexico Border Region
}

\author{
Mary-Katherine Smith • David Line Denali
}

Received: 12 February 2014 /Revised: 3 April 2014 / Accepted: 22 May 2014 / Published online: 18 June 2014

(C) W. Montague Cobb-NMA Health Institute 2014

\begin{abstract}
Social media is changing how individuals gather information and relate to others. Public health professionals can use social media in their efforts to assess health needs, set policy, and communicate health concerns as they focus on protecting and improving the health of the community. It has been estimated that traditional health messaging campaigns reach less than $10 \%$ of the targeted population. The purpose of this article is to discuss ways that social media can be used as a tool to reach rural border health populations along the USA/Mexico border. The USA/Mexico border region is one of the fastest growing areas in the nation and infamous for health disparities due to low socio-economic conditions. The border region contains many rural areas; the rurality creates an additional barrier of distance and further increase of health disparities. Through well-developed and targeted social media campaigns, public health professionals can assess and develop effective health strategies to reach this hard-to-reach population and improve the health and quality of life for those living in the rural border region.
\end{abstract}

Keywords Rural health $\cdot$ Hispanic $\cdot$ Social media $\cdot$ Border health $\cdot$ Health education $\cdot$ Public health

The interaction among people in which they "create, share, and/or exchange information and ideas online in virtual communities and in virtual networks," is known as social media [1]. The development and growth of the social media phenomena over the last 10 years has been one of the most remarkable communication developments since the invention of the printing press [1]. Social media is changing how individuals gather information and relate to others. This gathering

M.-K. Smith $(\bowtie) \cdot$ D. L. Denali

School of Health Management, A.T. Still University, 210A S.

Osteopathy, Kirksville, MO 63501, USA

e-mail: mksmith@atsu.edu and conveying of information has created immense opportunities for public health professionals. "Public health is the science of protecting and improving the health of families and communities through promotion of healthy lifestyles, research for disease and injury prevention and detection and control of infectious diseases [2].” In contrast to its clinical counterpart which focuses on individuals and treatment, public health focuses on the prevention of negative and promotion of the positive determinants of community health [2]. This article explores the use of social media as a health assessment, policy development, and education tool to address community health issues along the USA/Mexico Border Region.

\section{Social Media in Public Health}

In order to improve the health of the community, public health has three main core functions; assessment, policy development, and assurance [3]. The core functions include efforts such as data/information gathering, policy development, and outreach [3]. Public health not only aims to improve the health of communities, but also strives to reduce health disparities [2]. In an effort to reduce health disparities, public health targets hard-to-reach populations with all three core functions. The phenomenon of social media can be used to improve the health of hard-to-reach populations, though the sharing and assessment of information, creation of evidence based policies, and by providing a support system to orchestrate positive health behavior changes with targeted messages. One of the most successful public health social media campaigns to date was the CDC "Zombie Apocalypse" campaign on preparedness 101, designed to encourage new audiences to learn about preparedness. This campaign included blogs, websites, Twitter, Facebook, and badges [4].

Well-developed and targeted health information, along with increased access to the internet and mobile devices 
allows for messages to be delivered directly to individuals faster than ever before [5]. Not only does the internet and social media allow for the quick delivery of targeted messages, they are also very cost effective [6]. For example, a "tweet" or Facebook post can be posted virtually free of charge, yet reach thousands in an instant. Complementing the ability to disseminate information is the ability to gather information from social media and internet sources. This allows for targeted messages to reflect the health needs of communities with a precision never before achievable.

\section{The Rise of Social Media}

"Social media are Internet sites where people interact freely, sharing and discussing information about each other and their lives, using a multimedia mix of personal words, pictures, videos and audio [7]." Social media got a slow start in 1969 with the development of CompuServe, and took off in exponential growth in 1994 as personal computers became common and then in the 2000s as cell phones and mobile communication devices proliferated [7]. Social media differs greatly from traditional media in many ways. Social media is accessed much more frequently than traditional methods. There is also an expectation from users that there are frequent updates and the ability to share with immediate results. Social media also reaches individuals and populations at a much faster rate than traditional methods [8] [9]. Internet users spend more time with social media sites than any other type of site. Total time spent on social media in the USA across computers and mobile devices increased by $37 \%$ to 121 billion minutes in July 2012 compared to 88 billion minutes in July 2011 [10]. Information regarding what and when social media information is accessed can be gathered by public health professionals and used to predict outbreaks, determine current health concerns, as well as assist health educators in targeting audiences. Google Trends is an example of social media surveillance outpacing traditional public health surveillance tools. A recent study has shown that Google trends predict influenza outbreaks days before traditional surveillance methods. By counting how many people are searching on Google for terms associated with the flu, public health officials can determine outbreak locations before the outbreaks occur [11]. Similarly, placing links to web pages on printed media can help determine the effectiveness of traditional forms and expand the quantity of information available to the interested person. Quick Response Codes or QR Codes are an example of this.

Aside from the more common forms of social media such as Twitter and Facebook, there are numerous other forms of technology, that in conjunction with social media, are also changing the way individuals receive health messages and access healthcare. Mobile health technology (mHealth) uses text messages to support patients with chronic disease and help them with treatment compliance [12]. mHealth is also used to engage individuals in behavior changes such as smoking cessation and healthy eating [12]. mHealth allows for the quick and timely delivery of daily support at increased convenience and lower cost. eHealth equity use is another form of social media increasing at rapid rates, this includes the use of apps and podcasts to access and manage health information [13]. This allows a patient to customize and learn about specific health interests and concerns. Both mHealth and eHealth have been especially successful in reaching vulnerable populations who are not likely to access preventive care or manage chronic conditions on a regular basis [12]. With the continued increase in the use of social media in public health, it is crucial to ensure that the public has the skill sets to use and access social media campaigns, this skill is known as eHealth Literacy and is defined as "the ability to seek, find, understand, and appraise health information from electronic sources and apply the knowledge gained to addressing or solving a health problem [14]."

Prior to the development and use of social media, traditional public health campaigns, messages, and communications, typically include mass media campaigns such as television and radio as well as small media efforts such as posters and fliers. Messages and campaigns often include community events such as health fairs and interpersonal communication in the form of hotlines [6]. The cost of this form of communication is high due to production and labor costs. These campaigns also had a low return on investment due to the number and percentage of people reached. Results from a study that reviewed the effectiveness of 22 traditional public health campaigns indicated a "median increase of 8.4 percentage points in the proportion of people engaging in a healthful behavior related to use of the product distributed [6]". This is a very low percentage of individuals reached compared to effort. With the continued decrease in public health funding, continued increase in chronic health issues and a widening gap of health disparities, it is vital to deliver well targeted messages to those most in need, while being budget conscious. As we can see from the research, traditional campaigns are not meeting the needs of the people or of public health professionals.

\section{Disparities in the USA/Mexico Border Region}

The USA/Mexico Border Region is considered "the area of land being $100 \mathrm{~km}$ north and south of the international boundary. It stretches approximately 2,000 miles from the southern tip of Texas to California [15]." Currently, over 13 million people live in the border region with $53 \%$ of them on the US side [16]. Populations along the border vary greatly from 0.28 persons per square mile in Kenedy County, Texas, to 670 
persons per square mile in San Diego County, California. The border population is one of the fastest growing in the nation, and this is causing unique strains and stresses on the healthcare system [16]. The border region is $50.7 \%$ Hispanic [17] and is also home to 26 US federally recognized indigenous tribes [16]. The region is considered medically underserved and impoverished; it contains 3 of the top 10 poorest counties in the USA; 21 of the 44 US counties in the border region are designated as economically distressed. The border region is notorious for high rates of uninsured individuals and for high rates of health disparities [15]. The health issues that are of the greatest concern and that demonstrate the greatest disparity in the USA/Mexico border region currently are: vaccine preventable illness, infectious disease such as TB and HIV/AIDS, vector-borne illness, chronic illness, and illnesses that spread through food and water [18]. Over 432,000 people live in over 1,200 "colonias" along the border region. Colonias are communities which are unincorporated, rural or semi-rural areas and are characterized by substandard housing and lack of public drinking water or waste water/sewage systems [15].

\section{Internet Access in the USA/Mexico Border Region}

Across the world, one in four individuals has access to internet and access continues to grow [19] [20]. Access along the USA/Mexico border region is even greater than this [21]. Internet access is part of the United Nations Millennium Development Goal 8, Target F which states, "In cooperation with the private sector, make available benefits of new technologies, especially information and communications" [22]. In response to this target, the World Summit of the Information Society has vowed "to connect villages ... health centres and hospitals with information and communication technology [ICTs]" by 2015 [23]. With increased internet access, we are seeing increased use of the internet as a source of finding health information [24] [25]. Among the USA/Mexico Border region we know that $100 \%$ of health practitioners have internet access either in their home, office, or mobile access. Despite the high poverty rates, much of the border population still has access to internet either at home, through an internet café or through their mobile devices. Mobile internet usage, such as internet on a phone or tablet device, is becoming standard practice where internet access has slow connection speeds and where access may not be wide spread. Globally, there are more than four billion mobile phone subscribers who use internet, and two thirds of them are in developing countries or populations demographically similar to what is found in the USA/Mexico border [20].

Hispanics, as a population group, spend more time online and on social media than their African American or White non-Hispanic counterparts. On average, $26.8 \%$ of Hispanic
Internet users spend six or more hours on social media sites per day versus $20.4 \%$ of African American Internet users and $8.5 \%$ of white non-Hispanics [26].

\section{Reaching "Hard-to-Reach Populations" within the USA/Mexico Border Region}

With the vast area, the extreme health disparities and the diverse population, it has been difficult for health professionals to reach many of the populations in the border region. Due to barriers such as time, cost, lack of infrastructure, available resources, languages spoken, and cultural beliefs, many public health messages do not reach the intended subpopulations. Although public health professionals cannot reach all individuals along the border region with traditional media campaigns, through careful targeted social media messages and techniques, they can assess and communicate with a much higher percentage of these individuals. An example of how to set up an effective social media campaign is the Food and Drug Administration (FDA)'s "The Real Cost" antismoking campaign [27]. To start the process, the FDA did an assessment of issues facing teens and teen smoking. The FDA then did a focus group on what matters to their target population, the teenagers. After this, they evaluated what format and what messages reach the teenagers. Then, the FDA crafted and sent messages to reach this sub-population. Then, the FDA tracked activity associated with the messages [28].

While this process seems extensive, it can be replicated on the local level. Here is one way to do this: Using Google Trends, search to determine if a health issue is an issue in your area or you could use more traditional methods to accomplish the same objective. For example, you could search for the term "breast cancer" on Google Trends. Then narrow the results down to your area and the last few years. A review of the USA/Mexico border region in Texas on Google Trends with the term "breast cancer" indicates a surge in searches every October from 2006 to 2013 [29]. You could use cancer rates from the BRFSS or research results to determine level of the issue. You might decide to proceed with a media campaign to increase cancer screening practices based on the findings that only $59.2 \%$ of Hispanic women over the age of 65 have had a mammogram in the past 2 years. In contrast, $84.2 \%$ of Non-Hispanic women from the same region have had a mammogram in the past 2 years. [30] With an awareness of the issue and a target date to start the campaign in September, you would interview the target population about reasons why they do not screen for breast cancer and their use of social media or other media outlets. Hispanic women over the age of 65 are not big social media users. However, their grandchildren are likely to use social media on a regular basis [21]. According to your experiences and research, Hispanics in this region tend to 
have close family relations [31]. Therefore, a social media campaign aimed at Hispanic females aged 14 to 30 with a message of getting grandmothers to have their mammograms would have a higher likelihood of success than traditional media formats. An example of part of this campaign could be the following tweet:

Nana, what are your \#cholesterol levels? When was the last time you did a \#BSE? And when is your next \#mammogram? Tell your Nana you love her; tell her about alas-wings.org.

Tweets like this expose risky behaviors of parents to the younger generation. As such, it can help start a discussion or even a bargain. As in, "If you get a mammogram, I will ..." In this manner, you can address health issues by surrogate.

To see if the program will work, ask your target population what forms of social media they use and if they would be willing to "friend" you on Facebook or "follow" you on Twitter. This will increase your potential for success by increasing the number of people who you are connected to and by determining which form of social media is popular in your target population. When doing this, consider using someone who is in this sub-population to help you.

Once the campaign has started, follow the activity associated with your social media efforts. Next, you would interview different people in your target younger population to see if they have seen your efforts. Then, return to your original population, Hispanic women 65 and older, and ask them if anyone has talked with them about breast cancer or the social media campaign. Finally, check with your original sources to determine if there is a change in screening or breast cancer rates.

\section{Risk, Limitations, and Challenges in Using Social Media for Health Education, Promotion and Communication}

While social media has many benefits in public health and reaching populations, it does not come without risks, limitations, and challenges. In an April 2013 article, researchers looked at the benefits and limitations of using social media [32]. One central reoccurring theme emerged regarding limitations and that is the concern of quality and lack of reliability. One of the benefits of social media is ease of use and low or no cost. This is also a limitation regarding quality and reliability. Because of the ease and cost, just about anyone can produce some form of social media; this makes it difficult to ensure that all information being produced is accurate and reliable. There is little control of who produces social media or what is published. As a public health professional we have no way to ensure that the public is receiving only accurate information from credible sources. Large volumes of information in social media are also a barrier and a challenge for many; especially if contradicting information is being published. The general public might have difficulty filtering through all the information and become confused.

\section{Future of Social Media in Public Health}

When strategically developed; social media can be an information equalizer among populations. The use of social media allows us to change the way we communicate [33]. We can now instantly send out a message in multiple languages, with different target pictures to different populations with the hit of a button. It allows us to electronically communicate "near face-to-face", instead of as an authority to the masses as we previously did through an agency or health billboard. Social media has changed communication between health professionals and the populations served from a "monologue to dialogue" [5]. As health professionals, we need to use this tool to reach the people and improve health outcomes and situations along the border region.

"All procedures followed were in accordance with the ethical standards of the responsible committee on human experimentation (institutional and national) and with the Helsinki Declaration of 1975, as revised in 2000 [5]. Informed consent was obtained from all patients for being included in the study."

Conflict of Interest Authors Smith and Denali declare no conflict of interest.

\section{References}

1. Ahlqvist, Toni, et al. Social media road maps exploring the futures triggered by social media. Vuorimiehentie: VTT Technical Research Center of Finland, 2008.

2. CDC Foundation. What is public health?. CDC Foundation. [Online] January 30, 2014. [Cited: January 30, 2014.] http://www. cdcfoundation.org/content/what-public-health.

3. Centers for disease control and prevention. Core functions of public health and how they relate to the 10 essential services. Core functions of public health and how they relate to the 10 essential services. [Online] January 28, 2014. http://www.cdc.gov/nceh/ehs/ephli/core ess.htm.

4. Centers for disease control and prevention office of public health preparedness and response. zombie preparedness. Zombie preparedness. [Online] February 1, 2014. http://www.cdc.gov/phpr/ zombies.htm.

5. McNab, Christine. What social media offers to health professionals and citizens. Bulletin of the World Health Organization. August 2009, Vol. 87, 8, pp. 565-644.

6. The guide to community preventive services. Effectiveness of health communication campaigns that include mass media and health related product distribution. Community guide news. [Online] October 18, 2014. [Cited: February 2, 2014.] http://www.thecommunityguide. org/news/2012/HealthCommunicationCampaigns.html.

7. Curtis, Anthony. The brief history of social media. The brief history of social media. [Online] 2013. [Cited: February 3, 
2014.] http://www2.uncp.edu/home/acurtis/NewMedia/ SocialMedia/SocialMediaHistory.html.

8. Finding high-quality content in social media. Agichtein, Eugene, et al., et al. 2008. International Conference on Web Search and Data Mining. pp. 183-193.

9. The social media guys. The complete guide to social media. November 8, 2010.

10. Nielsen. State of the media: the social media report 2012. 2012.

11. Google trends 2013-2014. Explore Google flu trends - United States 2013-2014. Explore flu trends-United States. [Online] February 9, 2014. [Cited: February 10, 2014.] http://www.google.org/flutrends/ us/\#US.

12. Gard, Anna. Bridging the disparities gap with mobile technology. Association of clinicians for the underserved. [Online] June 22, 2012. [Cited: 20 2014, 3.] http://clinicians.org/bridging-the-disparities-gapwith-mobile-technology-2/.

13. eHealth equity. eHealth equity. [Online] 2014. [Cited: 3 20, 2014.] http://ehealthequity.com/.

14. eHealth literacy: skills for consumer health in a networked world. Cameron, Norman and Skinner, Harvey. e9, s.l. : Journal of Medical Internet Research, 2006, Vol. 8.

15. United States-Mexico border health commission. Border region. [Online] 2014. [Cited: January 27, 2014.] http://www.borderhealth. org/border_region.php.

16. United States-Mexico border health commission. Health disparities and the US-Mexico challenges and opportunities. [Online] October 25, 2010. [Cited: January 28, 2014.] http://southern. arizonaindicators.org/sites/southern.arizonaindicators.org/files/ content/publications/United_States_Border_Health_Commission. pdf.

17. Hispanic health disparities on the US-Mexico border region. Anders, Robert. El Paso, Texas : s.n., 2014. Hispanic health disparities research center UT Houston School of Public Disparities Research Center Presentation.

18. Centers for disease control and prevention. United States-Mexico Public Health. [Online] September 26, 2013. [Cited: January 27, 2014.] http://www.cdc.gov/usmexicohealth/.

19. Internet World Stats. Usage and population statistics. [Online] February 6, 2014. [Cited: February 8, 2014.] www. internetworldstats.com.

20. International telecommunications unit. Measuring the information society the ICT development index. Geneva : International telecommunications Unit, 2009.
21. Moses, Lucia. Blacks and Hispanics are more likely than whites to use twitter graphic breakdown from pew by age, gender, race. [Online] March 6, 2013. [Cited: February 1, 2014.] http://www. adweek.com/news/technology/blacks-and-hispanics-are-morelikely-whites-use-twitter-147666.

22. United Nations. MDG monitor: track, learn, support. [Online] 2007. [Cited: February 1, 2014.] http://www.mdgmonitor.org/goal8.cfm.

23. Plan of Action. Geneva: s.n., 2003. World summit on the information society.

24. Fox, S and Jones, S. The social life of health information. s.1. : Pew Internet, 2009.

25. Van Uden-Kraan CF et al. Health-related internet use by patients with somatic diseases: frequency of use and characteristics of users. Inform Health Soc Care. 2009;34:18-29.

26. Editorial Staff. Sounding off Torres-harnessing the power of social media to engage with Hispanic consumers. Portada online. [Online] June 1, 2012. http://www.portada-online.com/2012/06/01/soundingoff-torres-harnessing-the-power-of-social-media-to-engage-withhispanic-consumers/.

27. Health and Human Services. The real cost. [Online] January 31, 2014. [Cited: February 9, 2014.] http://therealcost.betobaccofree. hhs.gov/.

28. Crosby, Kathy. FDA designs new smoking prevention ad strategy to target teens. [interv.] Judy Woodruff. s.l. : PBS NewsHour, February 4, 2014.

29. Google. Trends. Google trends. [Online] February 10, 2014. http:// www.google.com/trends/explore $\# \mathrm{q}=\% 2 \mathrm{Fm} \% 2 \mathrm{~F} 0 \mathrm{j} 8 \mathrm{hd} \&$ geo $=\mathrm{US}-$ TX-636\&cmpt=date.

30. Breast and cervical cancer screening practices among Hispanic and non-Hispanic women residing near the United States-Mexico border, 1999-2000. Coughlin, Steven S, et al., et al. 20, s.1. : Aspen Publications, March 5, 2003, Family Community Health, Vol. 23, pp. 130-139.

31. Ohio State University and family and consumer sciences. Understanding the Hispanic culture. [Online] 2013. [Cited: February 1, 2014.] http://ohioline.osu.edu/hyg-fact/5000/5237.html.

32. New dimension of health care: systematic review of the uses, benefits, and limitations of social media for health communication. Moorhead, Anne, et al., et al. e85, April 2013, Journal of Medical Internet Research, Vol. 15.

33. Social networking increases worldwide as sites increase their focus on cultural relevance. Lipsman, Andrew. Reston : Comscore, August 12, 2008, comScore. 